\title{
Patients' tolerance of bimanual lid retraction versus a metal speculum for intravitreal injections
}

\author{
This article was published in the following Dove Press journal: \\ Clinical Ophthalmology \\ 6 September 2016 \\ Number of times this article has been viewed
}

\author{
Khadijah Alattas \\ Department of Ophthalmology, \\ College of Medicine, King Abdulaziz \\ University, Jeddah, Saudi Arabia
}

Objective: To compare patients' acceptance of and correlate their pain level for bimanual versus metal speculum fixation in intravitreal injections.

Design: Prospective analysis.

Participants: Seventy-three eyes of 56 patients.

Methods: A questionnaire indicating patients' discomfort and pain grading immediately after intravitreal injections using either bimanual fixation or metal speculum fixation (Barraquer Wire Speculum).

Results: Fifty-six patients who underwent intravitreal injections were enrolled in this study for various conditions. Patients' overall pain and discomfort were as follows, right eye - bimanual was 0.3 on our grading scale with a standard deviation of 0.54 , right eye - metal was 1.6 on our grading scale with a standard deviation of 1.5 , left eye - bimanual was 0.41 on our grading scale with a standard deviation of 0.87 , and left eye - metal was 1.91 on our grading scale with a standard deviation of $1.14(P=0.003)$.

Conclusion: Patients who underwent bimanual fixation had a much more comfortable experience with less pain in comparison to patients who underwent metal speculum fixation.

Keywords: AMD, diabetic retionpathy, Avastin, eye injection

\section{Introduction}

As ophthalmic care has been progressing in recent years with the breakthrough of intravitreal injections, and as more and more patients are having that procedure and causing an increase in the number of these procedures, ensuring the patient has the best possible experience with minimal pain and discomfort has become essential. Finemen et al's ${ }^{1}$ study emerged comparing patients' pain and discomfort threshold correlated with their eye fixation method - bimanual fixation or metal fixation, here we discuss patients' reactions comparing these two entities together. The speculum has the advantage of freeing the physician's hands and is able to function in a better, wider field, while keeping the eyelids and possible pathogens away from the injection site, using a modified grading scale from Rahimy et al's $\mathrm{s}^{2}$ study, as Tailor et $\mathrm{al}^{3}$ found that a metal speculum can lead to patient discomfort.

\section{Methods}

A single center prospective questionnaire grading the patients' discomfort and pain levels in a step-wise approach to the procedure, ranging from eyelid retraction to the end of the intravitreal injection procedure was employed. Approval from King Abdulaziz Univeristy Hospital ethics board was obtained for this study. All participants provided written informed consent to be included in the study. Seventy-three eyes of 56 patients were enrolled in this study, 46 patients underwent injections to
Correspondence: Khadijah Alattas Department of Ophthalmology, College of Medicine, King Abdulaziz University, PO Box 80208, Jeddah 21589, Saudi Arabia

Email dr_keka_y@hotmail.com 
Table I Overall pain scale results

\begin{tabular}{lll}
\hline Variables & Mean \pm SD & (Min-Max) \\
\hline Pain eyelid retraction OD & $0.21 \pm 0.8$ & $(0-5)$ \\
Pain povidone iodine OD & $0.40 \pm 0.6$ & $(0-2)$ \\
Anesthesia application OD & $0.11 \pm 0.3$ & $(0-1)$ \\
Intravitreal injection OD & $1.4 \pm 1.2$ & $(0-5)$ \\
Overall OD & $0.64 \pm 1.0$ & $(0-5)$ \\
Pain eyelid retraction OS & $0.45 \pm 0.9$ & $(0-3)$ \\
Pain povidone iodine OS & $0.45 \pm 0.6$ & $(0-2)$ \\
Anesthesia application OS & $0.10 \pm 0.3$ & $(0-1)$ \\
Intravitreal injection OS & $1.1 \pm 1.0$ & $(0-3)$ \\
Overall OS & $1.0 \pm 1.2$ & $(0-4)$ \\
\hline
\end{tabular}

Note: Grading scale from 0 to 5 with 0 correlating to no pain or discomfort and 5 correlating to the maximum quantity of pain or discomfort, as presumed by the patient.

Abbreviations: Max, maximum; min, minimum; OD, right eye; OS, left eye; SD, standard deviation.

their right eye, of these 12 had metal fixation and 34 had bimanual fixation; 27 patients underwent injections to their left eye, of these 12 were metal 15 and were bimanual fixation. Seventeen patients underwent injections in both eyes on the same day using different methods for both eyes, one eye being bimanual versus the other being metal, grading was done for each step of the procedure with a grading scale from 0 to 5 with 0 correlating to no pain or discomfort and 5 correlating to the maximum quantity of pain or discomfort as experienced by the patient. The next steps involved eyelid retraction, instillation of povidone iodine $5 \%$, topical anesthesia application, intravitreal injection, and grading of overall pain and discomfort.

\section{Results}

Our results showed a great majority of patients preferred the bimanual technique (75.4\%) in comparison to the metal speculum (15\%) with the remainder having no particular favorite. Of the patients, $86.2 \%$ had undergone a previous injection, $87.9 \%$ of the patients were injected for diabetic

Table 2 Right eye pain score results

\begin{tabular}{llll}
\hline Variables & \multicolumn{2}{l}{ Right eye (OD) pain score } & P-value \\
\cline { 2 - 3 } & $\begin{array}{l}\text { Bimanual } \\
\text { fixation }\end{array}$ & $\begin{array}{l}\text { Metal speculum } \\
\text { fixation }\end{array}$ & \\
\hline Pain eyelid retraction & $00 \pm 0.00$ & $0.83 \pm 1.5$ & $0.003^{* *}$ \\
Pain povidone iodine & $0.38 \pm 0.61$ & $0.42 \pm 0.52$ & 0.84 \\
Anesthesia application & $0.06 \pm 0.25$ & $0.25 \pm 0.45$ & 0.08 \\
Intravitreal injection & $0.94 \pm 0.84$ & $2.6 \pm 1.2$ & $0.001 * * *$ \\
Overall & $0.31 \pm 0.54$ & $1.6 \pm 1.5$ & $0.001 * * *$ \\
\hline
\end{tabular}

Notes: Data shown as mean \pm SD or $P$-value. **Significant $P$-value less than 0.01 ; ***extremely significant $P$-value less than 0.001 . Grading scale from 0 to 5 with 0 correlating to no pain or discomfort and 5 correlating to the maximum quantity of pain or discomfort, as presumed by the patient.
Table 3 Left eye pain score results

\begin{tabular}{llll}
\hline Variables & \multicolumn{2}{l}{ Left eye (OS) pain score } & P-value \\
\cline { 2 - 3 } & $\begin{array}{l}\text { Bimanual } \\
\text { fixation }\end{array}$ & $\begin{array}{l}\text { Metal speculum } \\
\text { fixation }\end{array}$ & \\
\hline Pain eyelid retraction OS & $0.18 \pm 0.39$ & $0.83 \pm 1.2$ & $0.004^{* *}$ \\
Pain povidone iodine OS & $0.47 \pm 0.72$ & $0.42 \pm 0.52$ & 0.83 \\
Anesthesia application OS & $0.06 \pm 0.24$ & $0.17 \pm 0.39$ & 0.37 \\
Intravitreal injection OS & $0.53 \pm 0.62$ & $1.92 \pm 0.99$ & $0.001^{* * *}$ \\
Overall OS & $0.41 \pm 0.87$ & $1.91 \pm 1.14$ & $0.001^{* * *}$ \\
\hline
\end{tabular}

Notes: Data shown as mean $\pm \mathrm{SD}$ or $P$-value. **Significant $P$-value less than 0.01 ; ***extremely significant $P$-value less than $0.00 \mathrm{I}$. Grading scale from 0 to 5 with 0 correlating to no pain or discomfort and 5 correlating to the maximum quantity of pain or discomfort, as presumed by the patient.

macular edema. The overall pain scale is shown in Table 1, metal speculum eyelid retraction in the right eye scored a low pain score but scored zero in the bimanually fixated eye with a $P$-value of less than 0.003 , povidone iodine $5 \%$ and anesthesia application were comparable in both eyes, intravitreal injection showed a significant $P$-value with a lower pain score in the bimanually fixated eye $(0.94 \pm 0.84)$ compared to the metal speculum fixated eye $(1.6 \pm 1.5)$ with a $P$-value less than 0.001 .

Metal speculum eyelid retraction in the left eye scored a low pain score, but the pain score was even less in the bimanually fixated eye with a $P$-value of less than 0.04 ; povidone iodine $5 \%$ and anesthesia application were comparable in both eyes, intravitreal injection showed a significant $P$-value with a lower pain score in the bimanually fixated eye $(0.53 \pm 0.62)$ compared to the metal speculum fixated eye (1.91 \pm 1.14$)$ with a $P$-value less than 0.001 being statistically significant; for detailed description see Tables 2 and 3.

\section{Conclusion}

Patients preferred injections using the bimanual fixation method much more than the metal speculum method, a larger study sample is needed in future studies, although according to our study it appears to be statistically significant.

\section{Acknowledgment}

The author thanks Khaid Allam for his help.

\section{Disclosure}

The author reports no conflicts of interest in this work.

\section{References}

1. Fineman MS, Hsu J, Spirn MJ, Kaiser RS. Bimanual assisted eyelid retraction technique for intravitreal injections. Retina. 2013;33(9): 1968-1970. 
2. Rahimy E, Fineman MS, Regillo CD, et al. Speculum versus bimanual lid retraction during intravitreal injection. Ophthalmology. 2015; 122(8):1729-1730.
3. Tailor R, Beasly R, Yang Y, Narendran N. Evaluation of patients' experiences at different stages of intravitreal injection procedure - what can be improved? Clin Ophthalmol. 2011;5:1499-1502.
Clinical Ophthalmology

\section{Publish your work in this journal}

Clinical Ophthalmology is an international, peer-reviewed journal covering all subspecialties within ophthalmology. Key topics include: Optometry; Visual science; Pharmacology and drug therapy in eye diseases; Basic Sciences; Primary and Secondary eye care; Patien Safety and Quality of Care Improvements. This journal is indexed on

Submit your manuscript here: http://www.dovepress.com/clinical-ophthalmology-journal

\section{Dovepress}

PubMed Central and CAS, and is the official journal of The Society of Clinical Ophthalmology (SCO). The manuscript management system is completely online and includes a very quick and fair peer-review system, which is all easy to use. Visit http://www.dovepress.com/ testimonials.php to read real quotes from published authors. 